\title{
The treatment of acute appendicitis in two age-based groups during COVID-19 pandemic: a retrospective experience in a COVID-19 referral hospital
}

\author{
Giorgio Lisi ${ }^{1} \oplus$ - Michela Campanelli ${ }^{2} \cdot$ Maria Rosaria Mastrangeli ${ }^{1} \cdot$ Domenico Spoletini $^{1} \cdot$ Rosa Menditto $^{1}$. \\ Simona Grande ${ }^{2}$. Massimiliano Boccuzzi ${ }^{3}$. Michele Grande ${ }^{2}$
}

Accepted: 29 October 2021 / Published online: 4 November 2021

(c) The Author(s), under exclusive licence to Springer-Verlag GmbH Germany, part of Springer Nature 2021, corrected publication 2021

\begin{abstract}
Purpose During the past months, the Italian Government has reduced the restrictions and access to hospitals as well as outpatient. Since then, up to $40 \%$ of non-traumatic abdominal emergencies have had unusual delayed treatment. Given the rapidly evolving situation and the absence of evidence to support recommendations during the COVID-19 pandemic, it is useful to assess how the current situation is influencing the management of elderly patients with acute appendicitis.

Methods Between February 2020 and December 2020, all patients 18 years or older undergone appendectomy were included. Patients were divided in two age-based groups (young groups, YG; elderly group, EG). Surgical approach, hospital stay, post-operative complications, radiology reports, and histologic examination were included in the retrospective analysis.

Results One hundred eight patients underwent appendectomy, 81 patients into the YG, and 27 in the EG. Laparoscopy was performed in $87.7 \%$ of the YG and in $51.8 \%$ of the elderly $(p<0.000)$, while conversion to laparotomy was necessary in $3.7 \%$ in the YG vs $22.3 \%$ of the other group ( $p<0.009$ ). Open procedures were more frequent in the EG, $25.9 \%$ vs $8.6 \%$ ( $p$ value $<0.05)$. No mortality rate was reported in both groups; moreover, the mean hospital stay was greater in the EG than the YG $(p<0.000)$.

Conclusion Our data highlighted a partial delay in diagnosis in the elderly group, and an increase in complicated appendicitis also demonstrated by the need for conversion to laparotomy despite no significant relationship between these findings and the histologic examination was reported.
\end{abstract}

Keywords COVID-19 $\cdot$ Acute appendicitis $\cdot$ Appendectomy $\cdot$ Elderly $\cdot$ Laparoscopy $\cdot$ Surgery

\section{Introduction}

Acute appendicitis (AA) is a common cause of abdominal pain, however one of the most frequent emergency surgical conditions, which can turn into perforation and peritonitis. The male/female ratio is $1.4 / 1$ with a permanent risk of $8.6 \%$ in males and $6.7 \%$ in females, while the risk of undergoing

Giorgio Lisi

giolimas06@yahoo.it

1 Department of Surgery, Sant'Eugenio Hospital, Piazzale dell'Umanesimo 10, 00144 Rome, Italy

2 Emergency Surgery Unit, University Hospital of Tor Vergata, viale Oxford 81, 00133 Rome, Italy

3 Department of Surgery, San Sebastiano Hospital, via Tuscolana 1, 00046 Frascati, Rome, Italy appendectomy is much lower in men than in women (12\% vs $23 \%$, respectively) [1-3]. Diagnosis is made through medical history, clinical examination, laboratories, and radiology. The role of ultrasound and CT scan is a current controversy. Appendicitis is more commonly diagnosed in young patients (mainly males); in fact almost $70 \%$ concerns those under 30, while in the elderly over 60 years the diagnosis occurs in 5-10\% [4-8]. In recent years, there has been a progressive increase in the incidence of appendicitis among the elderly, probably related to the increase in average life expectancy and to the improvement of imaging techniques. In 2010, a US study estimated that the slot for those over 65 will double from 40 to 80 million by 2040 [3, 5-7].

Complicated appendicitis is higher in elderly than in young patients with perforation rate of $70 \%$ and a morbidity rate of $48 \%[9,10]$. The reasons were probably due to the atypical clinical onset and a delayed diagnosis. Indeed, 
a late diagnosis could lead to abscess formation, perforation, and generalized peritonitis.

Treatment of AA consists of two choices: conservative and/or surgical treatment. In the last decade, conservative therapy has been proposed as a valid choice instead of the surgical approach in case of uncomplicated appendicitis, although it has also played a major role in patients with abscess or phlegmon $[9,11]$. Surgical treatment consists of appendectomy, which is a safe procedure with a mortality rate of 0.08 to $0.4 \%$ for uncomplicated appendicitis [5-7]. Early appendectomy was the first choice of treatment in patients with suspected or confirmed AA, although there is a high rate of negative appendectomies $(15-25 \%)[12$, 13]. Recently, the laparoscopic approach is preferred to laparotomy both in adults and pediatric patients as well as during the COVID-19 pandemic despite preliminary studies have not recommended laparoscopy [14-17].

However, the debate on appendectomy timing, safety of hospital discharge, treatment recommendations, and post-operative strategy is still open. During the last year, the University Hospital of "Tor Vergata" (Rome, Italy) has been named "Covid Hospital-4", the fourth referral hospital for COVID-19-positive patients in Rome. In recent months, the Italian Government has reduced restrictions and access to hospitals as well as to outpatients. Since then, up to $40 \%$ of non-traumatic abdominal emergencies have undergone unusual delayed treatment [18]. In all cases, the fever had been present for several days prior to admission. The delay was partly related to the choice of the patient, who preferred to stay at home until symptoms worsened, and partly due to the waiting list for the COVID-19 test in the emergency room, almost half of the centers reported emergency associated with more severe presentation due to diagnostic delay [19]. Many patients with fever have asked the authorities not to go to the hospital if they do not have breathing difficulties. In these patients, the fever may not be caused by COVID-19-related pneumonia but by an abdominal infection. There are also numerous patients whose diagnostic delay is related to the time spent in the emergency room, due to the scarcity of available beds due to the outbreak.

Given the rapidly changing situation and the lack of evidence to support the recommendations during the COVID19 pandemic, it might be useful to assess how the current situation influenced the management of AA in elderly as also in younger patients, as no firm conclusions can be drawn at this time.

The purpose of this retrospective analysis was to determine if there was a delay in the presentation and diagnosis of acute appendicitis in the elderly during the COVID-19 pandemic, to investigate how age-related differences could influence clinical onset and to consider the best diagnostic tool surgical strategy and potential adverse events.

\section{Materials and methods}

All patients over 18 years who underwent appendectomy at the Emergency Surgery Unit of the University of Tor Vergata between February 2020 and December 2020 were included in this study. Patient demographics and COVID status with pre-operative rapid antigen test; pre- and post-operative management, surgical approach, and length of hospital stay; and 30-day complications were recorded. The study was approved by the Local Ethics Committee, and all procedures were performed by the same senior surgeon (MG). We excluded all patients who underwent appendectomy for malignant disease, appendectomy performed in an elective surgery setting. According to the recent study by Kurian et al. [20], patients were divided into two age-based groups, and 68 years old is reported to be the ideal cut-off between young and elderly patients undergoing gastrointestinal procedures. The retrospective analysis included 81 patients in the young group and 27 in the elderly group. The items considered in the study were age, sex, temperature, $\mathrm{C}$-reactive protein (CRP), and white blood cells (WBC) at the time of admission and radiological reports. Other data included were surgical approach (laparoscopy and laparotomy), hospital stay, and post-operative adverse events. In addition, all patients were divided into three further groups based on histological analysis: normal appendix, acute appendicitis, and complicated appendicitis (gangrene, perforated, abscess).

\section{Statistical analysis}

SPSS ${ }^{\circledR}$ version 17.0 (IBM, Armonk, NY, USA) was used for the statistical analysis. Data were expressed in median with interval. Mann-Whitney $U$ test was used to analyze the quantitative variables and chi-square test for the nonquantitative variables. $p<0.05$ was considered statistically significant.

\section{Results}

The elderly group (EG) included 27 patients with a mean age of $74.83 \pm 5.62$ years old. Of these, 14 were males $(51.8 \%)$ with a mean age of $74 \pm 4.3$ and 13 females (48.2\%) with a mean age of $75.67 \pm 7.47$ years.

The young group (YG) consisted of 81 patients younger than 68 years old with a mean age of $33 \pm 14.26$ years. The males were $50(61.7 \%)$ with a mean age of $33 \pm 13.82$, and the females were 31 with a mean age of $33 \pm 14.93$ years. Of the 108 patients tested for COVID-19 at admission, none of the patients tested positive. As shown in Table 1, WBC at admission were similar in both groups $(14.5 \pm 7.6$ 
Table 1 Pre- and post-operative data. Pts patient, Yrs years, $C R P$ $\mathrm{C}$-reactive protein

\begin{tabular}{|c|c|c|c|}
\hline & Pts $>68$ years $(27)$ & Pts $\leq \mathbf{6 8}$ years $(81)$ & $p$ value \\
\hline \multicolumn{4}{|l|}{ Clinical exams } \\
\hline $\mathrm{WBC}(\mathrm{mila} / \mu \mathrm{L})$ & $14.5 \pm 7.6$ & $13.96 \pm 4.19$ & 0.08 \\
\hline $\mathrm{CRP}(\mathrm{mg} / \mathrm{L})$ & $163.08 \pm 103.81$ & $72.86 \pm 81.21$ & $<0.001$ \\
\hline Temperature $\left({ }^{\circ} \mathrm{C}\right)$ & $36.9 \pm 0.78$ & $37.01 \pm 0.66$ & 0.06 \\
\hline \multicolumn{4}{|l|}{ Pre-operative imaging } \\
\hline US (\%) & 0 & $57(70.4)$ & / \\
\hline $\mathrm{CT}(\%)$ & $27(100)$ & $24(29.6)$ & $<0.02$ \\
\hline $\mathrm{US}+\mathrm{CT}(\%)$ & 0 & $14(17.3)$ & / \\
\hline \multicolumn{4}{|l|}{ Surgical approach } \\
\hline Laparoscopy (\%) & $14(51.8)$ & $71(87.7)$ & $<\mathbf{0 . 0 0 0}$ \\
\hline Open $(\%)$ & $7(25.9)$ & $7(8.6)$ & $<0.05$ \\
\hline Conversion to open (\%) & $6(22.3)$ & $3(3.7)$ & $<0.009$ \\
\hline \multicolumn{4}{|l|}{ Histologic examination } \\
\hline Appendicitis (\%) & $4(14.8)$ & $7(8.6)$ & 0.07 \\
\hline Acute appendicitis (\%) & $7(25.9)$ & $30(37)$ & 0.12 \\
\hline Complicated appendicitis (\%) & $16(59.3)$ & $44(54.4)$ & 0.06 \\
\hline \multicolumn{4}{|l|}{ Post-operative data } \\
\hline Major complications (\%) & $1(3.7)$ & $3(3.7)$ & 0.15 \\
\hline Minor complications (\%) & 0 & $10(12.35)$ & l \\
\hline Mortality (\%) & 0 & 0 & l \\
\hline Mean hospital stay (\%) & $5.64 \pm 2.67$ & $3.75 \pm 1.95$ & $<0.000$ \\
\hline
\end{tabular}

vs $13.96 \pm 4.19, p=\mathrm{ns})$, while CRP was higher in the EG than the YG $(163.08 \pm 103.81$ vs $72.86 \pm 81.21 ; p<0.001)$, but body temperature did not show significant changes in either group $\left(36.9{ }^{\circ} \mathrm{C} \pm 0.78\right.$ in $\mathrm{EG}$ vs $37.01{ }^{\circ} \mathrm{C} \pm 0.66$ in $\mathrm{YG} ; p=\mathrm{ns})$. Each patient was given the same antimicrobial therapy: 3rd generation cephalosporin and metronidazole, started from the time of diagnosis until the discharge. Preoperative ultrasound (US) was the only radiological exam performed on $70.4 \%$ (57 out of 81 ) of the YG despite CT scan was needed after US in $17.3 \%$ (14 out of 81 ), while all patients of the EG underwent CT scan (100\% vs $29.6 \%$, $p<0.02)$.

Laparoscopy was performed in $87.7 \%$ of the YG; conversely, it was completed in $51.8 \%$ of cases in the elderly ( 71 vs $14, p<0.000$ ), while conversion to laparotomy was necessary in $3.7 \%$ of the YG than the $22.3 \%$ in the EG (3 vs $6, p<0.009)$. Finally, open approach was more frequent in EG $(25.9 \%)$ than the YG $(8.6 \%)$. Complicated appendicitis occurred in 16 of $27(59.3 \%)$ patients in the elderly and in 44 of $81(54.4 \%)$ in the YG although no significant relationship between these findings and the histological analysis was reported.

Among post-operative complications, one patient of the EG underwent a percutaneous drainage for a pelvic abscess, while in YG 3 major complications were occurred. Of these, two pelvic abscesses treated with percutaneous drainage were reported, and one patient underwent emergency surgery due to the strangulation of the port-site incisional hernia although no small bowel resection was performed. Changes in antimicrobial therapy and delayed hospital discharge due to fever, elevated inflammatory values, pelvic effusion, or surgical site infection were reported in 10 of 81 patients $(12.35 \%)$ in the YG. Of these, one case of post-peritonitis pneumonia occurred, while no minor complications in the EG were detected. No mortality rate was reported in either group, moreover the mean hospital stay was higher in EG than in YG (5.64 days vs 3.75 days, $p<0.000)$.

\section{Discussion}

The outbreak resulted in a significant decrease in the demand for outpatient health services. At our institution, we have noticed a decrease in the total number of emergency, and we have also reported patients with advanced acute disease. One of them was acute appendicitis, which is among the most common causes of acute abdominal pain. Appendicitis can evolve rapidly, with a perforation rates from 16 to $40 \%$, and it is associated with increased morbidity and a $5 \%$ mortality rate [21].

In Italy we are taking care of increasingly elderly patients in elective surgery even in emergencies. The aim of our retrospective analysis was to verify the clinical onset and response to surgical treatment in two age-based groups undergone appendectomy for acute appendicitis during the 
pandemic also by comparing our results with the international literature.

According to our data, there were no significant differences between the admission parameters, even if the clinical onset in elderly patients was often localized throughout the abdomen; furthermore, no significant statistical differences in terms of WBC, CRP, and body temperature were reported. Our results suggest that US was unsatisfactory in the elderly and $\mathrm{CT}$ was often required for a complete diagnosis (performed in all EG versus YG, $p>0.02$ ).

Conversely, the US was more frequent in YG $(67.9 \%)$ as a single diagnostic tool; Segev et al. [22] hypothesized the use of CT scan in the elderly population might be due to the clinical onset, often more complicated by previous gastrointestinal diseases.

According to our analysis, we could confirm that CT scan is the better diagnostic exam for AA in elderly because of the risk malignant diseases; moreover, other exams may not be useful and might delay the time to diagnosis with the risk of a worse clinical scenario [23-25]. Di Saverio et al. [21] in their recent analysis have demonstrated that the volume of radiological examinations for acute appendicitis decreased overall and the proportion of severe cases increased during the acute pandemic period. The results of their study showed a reduction of $61 \%$ in the total number of abdominal CT scans performed in patients with signs of appendicitis. However, those diagnosed with appendicitis by $\mathrm{CT}$ are presenting at later stages with greater disease severity results which are congruent with the initial hypothesis that people are postponing visiting the emergency room until their symptoms become severe during the acute pandemic period.

Contrary to the few study published, Turanli et al. [26] analyzed two hundred and fourteen patients before and during the pandemic. Although there was a slight increase in perforation during the pandemic period, this negativity was not statistically significant $(p=0.58)$; they concluded that there was no difference before and during the outbreak in the rate of perforated appendicitis in patients who were referred from other pandemic hospitals (29.4\%) and those admitted via their own emergency room (16.6\%) during the pandemic period $(p=0.27)$.

These data referred to a specific sample size with a median age of 39 years old; it may be a confounding factor and may reduce the power of the analysis as well as underrate the complications associated with acute appendicitis in elderly.

According to the literature [27-29], complicated appendicitis is mostly reported in elderly (39.2\%) than the young patients (39.2\% vs $10.5 \%)$; conversely in our sample size, complicated appendicitis (gangrenous, perforated, or with peri-appendicular abscess) was reported in $59.3 \%$ of the EG (16 of 27 patients) and in $54.4 \%$ of the YG (44 of
81 patients), despite this difference was not statistically significant.

Most of the young patients were treated laparoscopically (87.7\%), while $51.8 \%$ of elderly underwent a laparoscopic procedure; this data may demonstrate that laparoscopy represents the most used approach regardless of age.

In addition, Zhou and Cen [30] in their recent retrospective analysis of 67 patients with a mean age of 40.9 years old reported that the ratio of open appendectomies was higher than a pre-pandemic period; therefore, the amount of blood loss increased due to the surgical method. Furthermore, the higher proportion of perforated appendicitis was also an important cause of increased blood loss.

Conversion to laparotomy was higher in the EG than the YG $(22.3 \%$ vs $3.7 \% ; p<0.000)$, confirming what is reported in literature [26, 30, 31]; moreover, in six patients of the EG, laparoscopy was converted to laparotomy because of a complicated scenario confirmed by histological exam (abscess and acute appendicitis with wide wall necrosis).

Recently, Javanmard-Emamghissi [32] in his UK cohort study analyzed 500 patients from 48 sites affected by acute appendicitis and treated conservatively or surgically; nevertheless, a previous survey in Ireland [33] showed that 54\% of patients with acute appendicitis treated conservatively had ongoing discomfort on follow-up post-discharge, and $63 \%$ would choose up-front appendicectomy if they could decide again.

Despite Javanmard-Emamghissi included all patients under 50 years old, he reported that two hundred and seventy-one patients (54\%) were initially treated conservatively, with 26 (10\%) cases progressing to an operation that was performed laparoscopically in $44 \%$ of patients (93/211). At 30 days, complications were significantly higher in the operative group ( $p<0.001)$; this finding might be due to an increase of laparotomy that it was not reported in our EG. Within this cohort study, 56\% of patients (133/237) had an open procedure. This is at significant odds with UK practice prior to the pandemic, where only a small number of patients were having open procedures $(0.4 \%)$ [34]. It is likely due to guidance issues that suggested laparoscopic surgery should be avoided due to concerns about aerosol generating procedures. These findings were also confirmed in the recent ACIE Appy Study where Ielpo B and co-authors highlighted that one-third of surgeons interviewed have changed their approach from laparoscopy to open surgery owing to the popular (but evidence-lacking) advice from expert groups during the initial phase of the pandemic although no agreement on how to filter surgical smoke plume during laparoscopy was identified [35].

The decision of proceeding straight to laparotomy in both groups was based on the clinical onset of the patient, the imaging, and the clinical evaluation. It was more frequent in the EG than the YG, 7 of 27 vs 7 of 81 , respectively $(p<0.05)$; this data may be partially related to the patient 
choice, preferring to stay at home until symptoms worsened, and in part due to the waiting list for the COVID-19 emergency room test, this choice was reported more frequent in elderly patients than the youngers [36, 37]. Contrary to what reported in the literature [38-40], in the EG, we carried no increase of morbidity which was reported higher in the YG. In fact, three major complications in the YG which required an invasive procedure were reported. Of these, in two cases, a percutaneous drainage due to a pelvic abscess was occurred, and one patient required a correction of a portsite incisional hernia reported 3 days after the discharge.

Mean hospital stay was longer in the elderly group (5.64 vs 3.75 days, $p<0.000$ ); this data is in line with the literature; moreover, it could be related with the great number of laparotomy or conversion to open procedure in the EG than the $\mathrm{YG}$ as also to the percentage of complicated appendicitis $(59.3 \%)$.

\section{Conclusions}

Our data showed a partial delay in diagnosis in the elderly group, and an increase in complicated appendicitis also demonstrated by the need for conversion to laparotomy despite no significant relationship between these findings and the histologic examination was reported.

Surgery-related morbidity is reduced for sure, but noninfectious illnesses have a great impact; these might be the reasons of a longer hospital stay. Laparoscopic approach is considered safe and associated to a lower risk of minor adverse events even in elderly. Nevertheless, the choice of the surgical procedure is up to the surgeon, who must consider clinical presentation, comorbidities, and imaging, and it should not be influenced by the patient age, despite it often was during the outbreak.

Acknowledgements LG and MC were responsible for manuscript writing, study design, and data collection; MG and MB were responsible for editing and drafting the manuscript; RM and SG performed the statistical analysis; MRM and DS performed the literature review; MG was responsible for data interpretation.

\section{Declarations}

Conflict of interest The authors declare no competing interests.

\section{References}

1. Society of American Gastrointestinal and Endoscopic Surgeons (2020) SAGES and EAES Recommendations Regarding Surgical Response to COVID-19 Crisis. https://www.sages.org/recommendations-surgicalresponse-covid-19/ [accessed 30 Mar 2020]

2. Di Saverio S, Khan M, Pata F, Ietto G, De Simone B, Zani E et al (2020) Laparoscopy at all costs? Not now during COVID-19 and not for acute care surgery and emergency colorectal surgery. J Trauma Acute Care Surg 88:715-718

3. Chang DC, Shiozawa A, Nguyen LL, Chrouser KL, Perler BA, Freischlag JA et al (2011) Cost of inpatient care and its association with hospital competition. J Am Coll Surg 212:12-19

4. Ferris M, Quan S, Kaplan BS, Molodecky N, Ball CG, Chernoff GW et al (2017) The global incidence of appendicitis: a systematic review of population-based studies. Ann Surg 266:237-241

5. Candi E, Tesauro M, Cardillo C, Lena AM, Schinzari F, Rodia G, Sica G, Gentileschi P, Rovella V, Annicchiarico-Petruzzelli M, Di Daniele N, Melino G (2018) Metabolic profiling of visceral adipose tissue from obese subjects with or without metabolic syndrome. Biochem J 475(5):1019-1035

6. Royal College of Surgeons of England (2020) Updated Intercollegiate General Surgery Guidance on COVID-19. https:// www.rcseng.ac.uk/coronavirus/joint-guidance-for-surgeons-v2/ [accessed 7 Apr 2020]

7. American College of Surgeons (2020) COVID-19 Guidelines for Triage of Emergency General Surgery Patients. https://www.facs. org/covid-19/clinical-guidance/elective-case/emergency-surgery [accessed 15 Apr 2020]

8. Grande M, Lisi G, Bianchi D, Bove P, Miano R, Esser A, De Sanctis F, Neri A, Grande S, Villa M (2015) Bilateral ureteral obstruction in children after appendectomy. Case Rep Surg 2015:740795

9. Coccolini F, Perrone G, Chiarugi M, Di Marzo F, Ansaloni L, Scandroglio I et al (2020) Surgery in COVID-19 patients: operational directives. World J Emerg Surg 15:25

10. An Y, Bellato V, Konishi T, Pellino G, Sensi B, Siragusa L et al (2020) Surgeons' fear of getting infected by COVID19: a global survey. Br J Surg 107:e543-e544

11. Snyder MJ, Guthrie M, Cagle S (2018) Acute appendicitis: efficient diagnosis and management. Am Fam Physician 98(1):25-33 900

12. Bhangu A, Søreide K, Di Saverio S, Assarsson JH, Drake FT (2015) Acute appendicitis: modern understanding of pathogenesis, diagnosis, and management. Lancet 386(10000):1278-1287

13. Jaschinski T, Mosch CG, Eikermann M, Neugebauer EAM, Sauerland S (2018) Laparoscopic versus open surgery for suspected appendicitis. Cochrane Database Syst Rev (11)

14. Lisi G, Campanelli M, Spoletini D, Carlini M (2020) The possible impact of COVID-19 on colorectal surgery in Italy. Colorectal Dis 22(6):641-642

15. Bellato V, Konishi T, Pellino G, An Y, Piciocchi A, Sensi B, Siragusa L, Khanna K, Pirozzi BM, Franceschilli M, Campanelli M, Efetov S, Sica GS (2020) S-COVID Collaborative Group. Screening policies, preventive measures and in-hospital infection of COVID-19 in global surgical practices. J Glob Health 10(2):020507

16. Sadr Azodi O, Andrén-Sandberg Å, Larsson H (2009) Genetic and environmental influences on the risk of acute appendicitis in twins. Br J Surg 96(11):1336-1340

17. Stolfi VM, Sileri P, Micossi C, Carbonaro I, Venza M, Gentileschi P, Rossi P, Falchetti A, Gaspari A (2008) Treatment of hemorrhoids in day surgery: stapled hemorrhoidopexy vs MilliganMorgan hemorrhoidectomy. J Gastrointest Surg 12(5):795-801

18. Patriti A, Baiocchi GL, Catena F, Marini P, Catarci M (2020) on behalf of the Associazione Chirurghi Ospedalieri Italiani (ACOI). Emergency general surgery in Italy during the COVID-19 outbreak: first survey from the real life. World J Emerg Surg 15:36

19. Lisi G, Campanelli M, Villa M, Grande S, Grande M (2020) Colorectal emergency surgery in a COVID-19 referral hospital during the phase 2 in Italy. Int J Colorectal Dis 35(11):2137-2138

20. Kurian AA, Wang L, Grunkemeier G, Bhayani NH, Swanstrom LL (2013) Defining the elderly undergoing major gastrointestinal resections: receiver operating characteristic analysis of a large ACS-NSQIP cohort. Ann Surg 258(3):483-489 
21. Di Saverio S, Podda M, De Simone B, Ceresoli M, Augustin G, Gori A, Boermeester M, Sartelli M, Coccolini F, Tarasconi A, De' Angelis N, Weber DG, Tolonen M, Birindelli A, Biffl W, Moore EE, Kelly M, Soreide K, Kashuk J, Ten Broek R, Gomes CA, Sugrue M, Davies RJ, Damaskos D, Leppäniemi A, Kirkpatrick A, Peitzman AB, Fraga GP, Maier RV, Coimbra R, Chiarugi M, Sganga G, Pisanu A, De' Angelis GL, Tan E, Van Goor H, Pata F, Di Carlo I, Chiara O, Litvin A, Campanile FC, Sakakushev B, Tomadze G, Demetrashvili Z, Latifi R, Abu-Zidan F, Romeo O, Segovia-Lohse H, Baiocchi G, Costa D, Rizoli S, Balogh ZJ, Bendinelli C, Scalea T, Ivatury R, Velmahos G, Andersson R, Kluger Y, Ansaloni L, Catena F (2020) Diagnosis and treatment of acute appendicitis: 2020 update of the WSES Jerusalem guidelines. World J Emerg Surg 15(1):27

22. Segev L, Keidar A, Schrier I, Rayman S, Wasserberg N, Sadot E (2015) Acute appendicitis in the elderly in the twenty-first century. J Gastrointest Surg 19(4):730-735

23. Farahbakhsh F, Torabi M, Mirzaee M (2020) A comparative study on the diagnostic validity of three scoring systems in the diagnosis of acute appendicitis in emergency centres. African J Emerg Med 10(3):132-135

24. Marin D, Ho LM, Barnhart H, Neville AM, White RR, Paulson EK (2010) Percutaneous abscess drainage in patients with perforated acute appendicitis: effectiveness, safety, and prediction of outcome. Am J Roentgenol 194(2):422-429

25. Guan W, Ni Z, Hu Y, Liang W, Ou C, He J, Liu L, Shan H, Lei CL, Hui DSC, du B, Li LJ, Zeng G, Yuen KY, Chen RC, Tang CL, Wang T, Chen PY, Xiang J, Li SY, Wang JL, Liang ZJ, Peng YX, Wei L, Liu Y, Hu YH, Peng P, Wang JM, Liu JY, Chen Z, Li G, Zheng ZJ, Qiu SQ, Luo J, Ye CJ, Zhu SY, Zhong NS (2020) China Medical Treatment Expert Group for Covid-19. Clinical characteristics of coronavirus disease 2019 in China. N Engl J Med 382(18): 1708-1720

26. Turanli S, Kiziltan G (2021) Did the COVID-19 pandemic cause a delay in the diagnosis of acute appendicitis? World J Surg 45(1):18-22

27. Köhler F, Acar L, van den Berg A, Flemming S, Kastner C, Müller S, Diers J, Germer CT, Lock JF, L'hoest H, Marschall U, Wiegering A (2021) Impact of the COVID-19 pandemic on appendicitis treatment in Germany-a population-based analysis. Langenbecks Arch Surg 9:1-7

28. Sohrabi C, Alsafi Z, Neill NO, Khan M, Kerwan A (2020) World Health Organization declares global emergency: a review of the 2019 novel coronavirus (COVID-19). Int J Surg 76:71-76

29. Flemming S, Hankir M, Ernestus RI, Seyfried F, Germer CT, Meybohm P, Wurmb T, Vogel U, Wiegering A (2020) Surgery in times of COVID-19-recommendations for hospital and patient management. Langenbeck's Arch Surg 405(3):359-364

30. Zhou Y, Cen LS (2020) Managing acute appendicitis during the COVID-19 pandemic in Jiaxing. China World J Clin Cases 8(19):4349-4359
31. Tankel J, Keinan A, Blich O, Koussa M, Helou B, Shay S, Zugayar D, Pikarsky A, Mazeh H, Spira R, Reissman P (2020) The decreasing incidence of acute appendicitis during COVID-19: a retrospective multi-centre study. World J Surg 44(8):2458-2463

32. Javanmard-Emamghissi H, Boyd-Carson H, Hollyman M, Doleman B, Adiamah A, Lund JN, Clifford R, Dickerson L, Richards S, Pearce L, Cornish J, Hare S, Lockwood S, Moug SJ, Tierney GM (2020) COVID: HAREM (Had Appendicitis, Resolved/ Recurred Emergency Morbidity/Mortality) Collaborators Group. The management of adult appendicitis during the COVID-19 pandemic: an interim analysis of a UK cohort study. Tech Coloproctol 15:1-11

33. Collard M, Lakkis Z, Loriau J, Mege D, Sabbagh C, Lefevre JH, Maggiori L (2020) Antibiotics alone as an alternative to appendectomy for uncomplicated acute appendicitis in adults: changes in treatment modalities related to the COVID-19 health crisis. J Visc Surg 157(3S1):S33-S42

34. RIFT study group (2019) Evaluation of appendicitis risk prediction models in adults with suspected appendicitis. Br J Surg 107:73-86

35. Ielpo B, Podda M, Pellino G, Pata F, Caruso R, Gravante G, Di Saverio S (2020) ACIE Appy Study Collaborative. Global attitudes in the management of acute appendicitis during COVID-19 pandemic: ACIE Appy Study. Br J Surg 8. https://doi.org/10.1002/ bjs.11999

36. Vanni G, Materazzo M, Pellicciaro M, Ingallinella S, Rho M, Santori F et al (2020) Breast cancer and COVID-19: the effect of fear on patients' decision-making process. In Vivo 34(3 Suppl):1651-1659

37. Mintz Y, Arezzo A, Boni L, Chand M, Brodie R, Fingerhut A (2020) Technology Committee of the European Association for Endoscopic surgery et al. A low cost, safe and effective method for smoke evacuation in laparoscopic surgery for suspected coronavirus patients. Ann Surg 272:e7-e8

38. Cash CL, Frazee RC, Smith RW, Davis ML, Hendricks JC, Childs EW et al (2012) Outpatient laparoscopic appendectomy for acute appendicitis. Am Surg 78:213-215

39. Jaschinski T, Mosch CG, Eikermann M, Neugebauer EA, Sauerland S (2018) Laparoscopic versus open surgery for suspected appendicitis. Cochrane Database Syst Rev 11:CD001546

40. Athanasiou C, Lockwood S, Markides GA (2017) Systematic review and meta-analysis of laparoscopic versus open appendicectomy in adults with complicated appendicitis: an update of the literature. World J Surg 41:3083-3099

Publisher's Note Springer Nature remains neutral with regard to jurisdictional claims in published maps and institutional affiliations. 